University of Nebraska - Lincoln

DigitalCommons@University of Nebraska - Lincoln

USDA Wildlife Services - Staff Publications

U.S. Department of Agriculture: Animal and Plant Health Inspection Service

2009

\title{
Alkaline Hydrolysis of Mouse-Adapted Scrapie for Inactivation and Disposal of Prion-Positive Material
}

R. G. L. Murphy

Center for Meat Safety and Quality, Department of Animal Sciences, Colorado State University, Fort Collins

J. A. Scanga

Center for Meat Safety and Quality, Department of Animal Sciences, Colorado State University, Fort Collins

B. E. Powers

Veterinary Diagnostics Laboratory, Colorado State University, Fort Collins

J. L. Pilon

USDA-APHIS-Wildlife Services

K. C. VerCauteren

USDA-APHIS-Wildlife Services, kurt.c.vercauteren@usda.gov

See next page for additional authors

Follow this and additional works at: https://digitalcommons.unl.edu/icwdm_usdanwrc

Part of the Environmental Sciences Commons

Murphy, R. G. L.; Scanga, J. A.; Powers, B. E.; Pilon, J. L.; VerCauteren, K. C.; Nash, P. B.; Smith, G. C.; and Belk, K. E., "Alkaline Hydrolysis of Mouse-Adapted Scrapie for Inactivation and Disposal of Prion-Positive Material" (2009). USDA Wildlife Services - Staff Publications. 960.

https://digitalcommons.unl.edu/icwdm_usdanwrc/960

This Article is brought to you for free and open access by the U.S. Department of Agriculture: Animal and Plant Health Inspection Service at DigitalCommons@University of Nebraska - Lincoln. It has been accepted for inclusion in USDA Wildlife Services - Staff Publications by an authorized administrator of DigitalCommons@University of Nebraska - Lincoln. 


\section{Authors}

R. G. L. Murphy, J. A. Scanga, B. E. Powers, J. L. Pilon, K. C. VerCauteren, P. B. Nash, G. C. Smith, and K. E. Belk 


\title{
Alkaline hydrolysis of mouse-adapted scrapie for inactivation and disposal of prion-positive material ${ }^{1}$
}

\author{
R. G. L. Murphy, ${ }^{*}$ J. A. Scanga, ${ }^{2}$ B. E. Powers, $\dagger$ J. L. Pilon, $\ddagger$ K. C. VerCauteren, + \\ P. B. Nash, + G. C. Smith, $*$ and K. E. Belk*3 \\ *Center for Meat Safety and Quality, Department of Animal Sciences, Colorado State University, Fort Collins, \\ CO 80523; †Veterinary Diagnostics Laboratory, Colorado State University, Fort Collins, CO 80523; \\ and $\ddagger$ USDA-APHIS-WS-National Wildlife Research Center, Fort Collins, CO 80521
}

\begin{abstract}
Prion diseases such as bovine spongiform encephalopathy, chronic wasting disease, and scrapie pose serious risks to human and animal health due to a host of disease-specific factors, including the resistance of infectious prions $\left(\mathrm{PrP}^{\mathrm{Sc}}\right)$ to natural degradation and to most commercial inactivation procedures. In an attempt to address this concern, a mouse model was used to compare the efficacy of an alkaline hydrolysis process with a simulated continuous-flow rendering treatment for disposal of $\mathrm{PrP}^{\mathrm{Sc}}$-infected biological material. Female C57/BL6 mice $(\mathrm{N}=120)$ were randomly divided into 4 treatment groups $(\mathrm{n}=30)$, and each mouse was injected intraperitoneally with their designated treatment inoculum. Treatment groups 1 and 2 served as the positive and negative controls, respectively. Group 3 was inoculated with rendered scrapie-positive mouse brain material to investigate the effectiveness of simulated continuous-flow rendering practices to reduce or eliminate $\operatorname{PrP}^{\mathrm{Sc}}$. Group 4 was inoculated with hydrolyzed scrapie-positive mouse brain material to determine the sterilizing effect of alkaline hydrolysis on $\mathrm{PrP}^{\mathrm{Sc}}$. Mice were monitored for
\end{abstract}

overt signs of disease, and those showing clinical signs were killed to prevent undue suffering. Brains were obtained from all mice that died (or were killed) and analyzed with an ELISA for the presence of $\mathrm{PrP}^{\mathrm{Sc}}$. Results indicated that the simulated continuous-flow rendering treatment used for preparing the rendering treatment group inoculum failed to completely eliminate $\operatorname{PrP}^{\mathrm{Sc}}$. Rendering delayed, but did not stop, clinical mouseadapted scrapie transmission. Compared with positive controls, the rendering treatment group experienced an approximate 45 - $\mathrm{d}$ average delay in days to death (250 vs. $205 \mathrm{~d}$ for positive controls; $P<0.0001)$ and a death loss of $73.9 \%(P=0.0094)$. Positive controls suffered $100 \%$ death loss. The results validated the efficacy of the alkaline hydrolysis treatment to inactivate all $\mathrm{PrP}^{\mathrm{Sc}}$ because no alkaline hydrolysis treatment group mice succumbed to the disease $(P<0.0001)$. Based on our results, alkaline hydrolysis should be considered by the animal rendering and beef packing industries as an alternative to incineration, landfill burial, and rendering for disposing of biological material potentially infected or contaminated with prion disease.

Key words: alkaline hydrolysis, commercial rendering, mouse model, prion inactivation

(C)2009 American Society of Animal Science. All rights reserved.

J. Anim. Sci. 2009. 87:1787-1793 doi:10.2527/jas.2008-1492

\section{INTRODUCTION}

After the discovery of bovine spongiform encephalopathy (BSE) in the United States, the Food and Drug Administration (FDA) published a proposed rule in the Federal Register in October 2005 that would prohibit certain cattle-derived materials from being included in the food and feed of all animals. The Final

\footnotetext{
${ }^{1}$ Funded by the Beef Checkoff.

${ }^{2}$ Current address: IEH Laboratories \& Consulting Group, 650 "O" Street, Greeley, CO 80631.

${ }^{3}$ Corresponding author: keith.belk@colostate.edu

Received September 18, 2008.

Accepted December 15, 2008.
}

Rule of the FDA was published on April 25, 2008 and will take effect on April 27, 2009 (DHHS-FDA, 2008). Under the enhanced feed regulations, the list of prohibited materials includes the entire carcass of BSEpositive cattle, the brains and spinal cords from cattle 30 mo of age and older, and "the entire carcass of cattle not inspected and passed for human consumption that are 30 mo of age or older from which brains and spinal cords were not removed" (among other identified materials; DHHS-FDA, 2008). Using USDA-NASS $(2008 \mathrm{a}, \mathrm{b})$ production and population statistics as well as the estimate reported by Roeber et al. (2001) for the percentage of nonambulatory disabled cattle offered for slaughter, the proposed rule of the FDA would prohibit the heads (including the brain) and spinal cords 
from the 6.23 million cows and bulls slaughtered; the entire carcass of approximately 1.86 million on-farm cattle mortalities; the entire carcass of approximately 49,800 nonambulatory cows and bulls condemned at antemortem inspection; all inedible offal products from noninspected slaughter facilities (150,000 cattle); and the heads (including the brain) and spinal cords from the small proportion of fed steers and heifers that are identified as being 30 mo of age and older from entering the animal feed system.

As a consequence of the new feed regulations, those cattle-derived materials prohibited from use in animal feeds will need to be disposed of by means other than rendering. Alkaline hydrolysis may have potential as an alternative to rendering for disposing of these potentially infectious tissues and animal carcasses. Therefore, the objective was to use a murine-based model to compare the efficacy of an alkaline hydrolysis process to a simulated continuous-flow rendering treatment for disposal of biological material infected with mouseadapted scrapie.

\section{MATERIALS AND METHODS}

Animal procedures were approved by the Colorado State University Animal Care and Use Committee and the USDA-APHIS-Wildlife Services-National Wildlife Research Center (NWRC) Institutional Animal Care and Use Committee.

\section{Treatment Group Inocula}

A known mouse-adapted scrapie-positive (C57/BL6) mouse brain (once passed from original mice obtained from Rocky Mountain Laboratories, Hamilton, MT) was removed from $-70^{\circ} \mathrm{C}$ storage (Revco, Thermo Electron Corporation, Asheville, NC) and homogenized into a slurry with a sterilized scalpel blade. The mouse brain homogenate was divided into 3 portions using a scientific balance (Sartorius Microbalance, Sartorius Ltd., Epsom, United Kingdom) and each portion $(\sim 0.110 \mathrm{~g})$ was randomly assigned to the positive control, rendering, or alkaline hydrolysis treatment groups. Homogenized treatment samples were placed in $200-\mu \mathrm{L}$ PCR tubes (Eppendorf North America, Westbury, NY) and refrozen at $-70^{\circ} \mathrm{C}$ until the next stage of the experiment. All treatment group inocula (including the inoculum for the negative control treatment group) were diluted after their respective treatments with $10 \%$ (wt/vol) PBS (Difco, Becton, Dickinson and Company, Franklin Lakes, NJ) to a final volume of $16 \mathrm{~mL}$. The final concentration of brain matter in the treatment group inocula was $6.25 \mu \mathrm{g}$ of brain matter per microliter.

Positive and Negative Control Treatment Groups. One-third of the scrapie-positive mouse brain homogenate was left untreated, transferred to a Dounce tissue grinder (Kimble/Kontes, Vineland, NJ), and ground further with a small volume of PBS. Af- ter homogenization, the brain homogenate solution was transferred to a sterile $50-\mathrm{mL}$ centrifuge tube (Thermo Fisher Scientific Inc., Waltham, MA), and additional PBS was added to achieve a final volume of $16 \mathrm{~mL}$. This sample served as the inoculum for the positive control treatment group.

The negative control treatment group mouse brain $(\sim 0.100 \mathrm{~g})$ originated from a known scrapie-negative mouse that was used in a previous study and known to never have been exposed to infectious prions $\left(\mathbf{P r P}^{\mathbf{S c}}\right)$. The mouse brain homogenate was diluted with PBS to achieve a final inoculum volume of $16 \mathrm{~mL}$.

Rendering Treatment Group. The purpose of the rendering treatment was to evaluate the efficacy of simulated continuous-flow rendering to inactivate $\mathrm{PrP}^{\mathrm{Sc}}$. The continuous cooker is an agitated vessel that raises the temperature of raw material to 115 to $145^{\circ} \mathrm{C}$ over a 45 - to 90-min period, evaporating moisture, as well as releasing fat from protein and bone for separation and recycling (Anderson, 2006). The continuous cooker was modeled in our laboratory after consultation with D. Kirstein (director of technical services, Darling International Inc., Des Moines, IA, personal communication) and K. Kage (plant manager, Darling International Inc., Denver, CO, personal communication). It was decided that a test tube apparatus, which cooked the scrapie-positive mouse brain homogenate in vegetable/animal shortening at a $2: 1$ shortening to brain ratio, was acceptable for representing the physical conditions of continuous-flow rendering.

A $500-\mathrm{mL}$ beaker containing $350 \mathrm{~mL}$ of shortening (Great Value, Wal-Mart Stores Inc., Bentonville, AR) was heated to $138^{\circ} \mathrm{C}$ and maintained between 120 and $138^{\circ} \mathrm{C}$ for the entire length of the rendering procedure. The temperature of the shortening was monitored by a suspended type- $\mathrm{K}$ thermocouple thermometer probe (Temptec Accutuff 340, Atkins Technical Inc., Gainesville, FL) placed in the beaker. A test tube containing shortening plus scrapie-positive mouse brain homogenate was suspended in the beaker of heated shortening and agitated periodically with a piece of steel wire. The temperature of the contents in the test tube was monitored by a suspended type-K thermocouple (Omega Engineering Inc., Stamford, CT) attached to a microprocessor thermometer (model HH21, Omega Engineering Inc.). The temperature of the test tube was monitored to ensure it did not exceed $135^{\circ} \mathrm{C}$, and the brain homogenate was cooked at this temperature for $45 \mathrm{~min}$.

After the test tube was removed from the apparatus and allowed to cool, the rendered brain homogenate was transferred to a freezer vial, mixed with $500 \mu \mathrm{L}$ of PBS, and frozen $\left(-70^{\circ} \mathrm{C}\right)$. On the day of inoculation, the rendered mouse brain homogenate was removed from frozen storage, ground with a Dounce tissue grinder, and diluted with $15.5 \mathrm{~mL}$ of PBS to create the rendering treatment group inoculum.

Alkaline Hydrolysis Treatment Group. The scrapie-positive mouse brain homogenate was removed 
from $-70^{\circ} \mathrm{C}$ storage, thawed to ambient temperature, and transferred to a $200-\mu \mathrm{L}$ PCR tube. Potassium hydroxide and distilled water were added to the brain homogenate in accordance with the operating instructions provided by the manufacturer of the alkaline hydrolysis unit (K. Morris, owner and chief operating officer, Hydrol-Pro Technologies Inc., Zephyr Hills, FL, personal communication). Technical grade $\mathrm{KOH}$ (50\% wt/wt; Univar USA Inc., Seattle, WA) was added to the PCR tube until it reached $8 \%$ of the weight of the mouse brain homogenate; distilled water was then added until it reached $12 \%$ of the combined sample weight $(\mathrm{KOH}$ plus brain homogenate). The PCR tube was placed inside a small stainless steel module, and the module was sealed to prevent the possibility that brain material could be expelled from it during the alkaline hydrolysis process. The module was transported to the alkaline hydrolysis unit (BioMEER, Hydrol-Pro Technologies Inc., Zephyrhills, FL) located at the Colorado State University James L. Voss Teaching Hospital Veterinary Diagnostics Laboratory in Fort Collins. The stainless steel module was fastened to the wastewater collection rim just beneath the lid, the vessel was sealed, and the alkaline hydrolysis process was initiated. The alkaline hydrolysis vessel is designed to operate at a peak temperature of $150^{\circ} \mathrm{C}$ and at a pressure of approximately 4.14 bars (60 PSI). The unit used in this study is designed to hydrolyze $1,818 \mathrm{~kg}(4,000 \mathrm{lb})$ of biological raw material (e.g., carcasses, necropsy samples, etc.) per cycle, in addition to the volume of $\mathrm{KOH}$ and water required in the hydrolysis process. In addition to the 9 to $12 \mathrm{~h}$ that is required to bring the vessel to the desired temperature, the efficiency of the wastewater removal step is highly variable, which can extend the hydrolysis procedure to 4 or $5 \mathrm{~d}$. Once the vessel reached its peak operating temperature $\left(150^{\circ} \mathrm{C}\right)$, it was maintained at this temperature until the wastewater removal step was completed (weight of hydrolyzed material is reduced to approximately $50 \%$ of the starting weight), at which time the effluent was discharged for disposal. The vessel was cooled until the module could be safely retrieved for transport back to the NWRC. The hydrolyzed material was transferred to a $50-\mathrm{mL}$ centrifuge tube and neutralized with PBS (pH 3). Once the hydrolyzed sample reached a neutral $\mathrm{pH}(\sim 8)$, neutral PBS was added to achieve a final inoculum volume of $16 \mathrm{~mL}$.

\section{Mouse Model}

Mice were maintained at the NWRC in cages under standard rodent housing conditions $\left(19\right.$ to $23^{\circ} \mathrm{C}$, ambient humidity, 12:12 light:dark cycle). Mice were monitored twice daily according to the guidelines established by the Animal Care and Use Committees at Colorado State University and the NWRC.

One hundred twenty female C57/BL6 mice (Hilltop Laboratory Animals, Hilltop, PA) were randomly divided into 4 groups of 30 mice each and housed in cages of
5 mice per cage. Cages of mice were randomly assigned to a treatment group using a random number generator. Cage numbers, except for those cages belonging to the negative control treatment group, were blinded to prevent prejudicial judgment of disease onset. Each mouse was inoculated by intraperitoneal injection with $500 \mu \mathrm{L}$ of their designated treatment material $(500 \mu \mathrm{L}$ $\times 30$ mice $=15 \mathrm{~mL}$ ). One milliliter from each treatment group inoculum was retained for Western blot analysis to identify the presence of $\mathrm{PrP}^{\mathrm{Sc}}$. Intraperitoneal inoculation was utilized for this study because it is a less invasive surgical procedure and has fewer complications associated with it than intracerebral inoculation. Hamir et al. (2008) explained that, whereas the intracerebral inoculation route gives the shortest incubation time, there are potential anesthesia-related complications and postprocedure complications such as intracranial hematomas and encephalitis that discourage its widespread acceptance. Three mice from each treatment group were killed at 2 and 4 mo after inoculation and their brain material collected for examination of $\operatorname{PrP}^{\mathrm{Sc}}$ using an ELISA and Western blot diagnostic assay. The remaining mice were monitored for overt signs of disease. Mice still living 18 mo postinoculation, which was the set study-termination date, were killed and analyzed for $\operatorname{PrP}^{\mathrm{Sc}}$.

To determine when mice were to be killed, several signs of clinical disease were monitored including rough coat, ataxia, kyphosis (hunched back), extreme lethargy, stiff tail, and collapsed abdomen. Suspect signs were awarded 1 point and distinct signs awarded 2 points. When a mouse attained a score of at least 6 for a period of 3 consecutive days, or was assigned a single 1-d score of 8 or more, the mouse was killed to prevent undue suffering. The brain was collected from mice that died (from any cause) or were killed and stored at $-70^{\circ} \mathrm{C}$ until assayed with an ELISA for the presence of $\operatorname{PrP}^{\mathrm{Sc}}$.

\section{Diagnostic Assays}

ELISA. The Bio-Rad CWD antigen test kit, ELISA (Bio-Rad Laboratories, Hercules, CA), was used to confirm scrapie diagnosis in end-stage clinical mice. All reagents, as well as the detailed assay procedure, are included with the purification and detection kits. Hibler et al. (2003) provides a very thorough explanation of the ELISA procedure that was helpful to this study.

Mouse brain tissue samples (350 mg $\pm 10 \mathrm{mg}$ ) were deposited into grinding tubes supplied by the manufacture and homogenized (TeSeE Precess 48 Homogenizer, Bio-Rad Laboratories) for $45 \mathrm{~s}$ at a speed setting of 6.5 units. Sample aliquots $(250 \mu \mathrm{L})$ were transferred to 2 -mL polypropylene micro test tubes, $250 \mu \mathrm{L}$ of reconstituted proteinase $\mathrm{K}$ solution was added to each tube, mixed by inversion, and incubated at $37^{\circ} \mathrm{C}$ in a microplate heating block for $10 \mathrm{~min}$. Clarifying solution $(250 \mu \mathrm{L})$ was added to each tube, again mixed by inversion, and centrifuged for $7 \mathrm{~min}$ at $15,000 \times g\left(20^{\circ} \mathrm{C}\right)$. After centrifugation, the supernatant was discarded 
and the micro test tubes were dried by inversion onto absorbent paper. Resolving buffer $(25 \mu \mathrm{L})$ was added to each sample and immediately incubated at $100^{\circ} \mathrm{C}$ for 5 min. After incubation, micro test tubes were mixed with a vortex agitator for $5 \mathrm{~s}$.

Sample diluent $(125 \mu \mathrm{L})$ was added to each micro test tube and mixed by pipetting the sample and diluent up and down in the tube. A $100 \mu \mathrm{L}$ aliquot of each diluted sample was added to a well in a microplate (individual wells coated with an anti-PrP monoclonal antibody), covered with adhesive film, and incubated $\left(37^{\circ} \mathrm{C}\right)$ for 75 min. After incubation, the adhesive film was removed, each well washed 3 times with $800 \mu \mathrm{L}$ of diluted wash solution using an automatic washer (model $1575 \mathrm{Im}$ munowash Microplate Washer, Bio-Rad Laboratories) and dried by inversion onto absorbent paper. Conjugate solution $(100 \mu \mathrm{L})$ was added to each well, then covered with adhesive film, and incubated for $60 \mathrm{~min}$ at $4^{\circ} \mathrm{C}$. At the conclusion of the incubation period, the adhesive film was removed, wells were washed 5 times with diluted wash solution $(800 \mu \mathrm{L})$, dried by inversion onto absorbent paper, and $100 \mu \mathrm{L}$ of substrate solution was added to each well. The microplate was then incubated in the dark at ambient temperature $\left(20^{\circ} \mathrm{C}\right)$ for 30 min. Next, $100 \mu \mathrm{L}$ of stop solution was added to each well, and the optical density was determined (model 550 Microplate Reader, Bio-Rad Laboratories) at 450 $\mathrm{nm}$ (test filter) and $620 \mathrm{~nm}$ (reference filter to reduce background absorbance).

Computer software (Microplate Manager Software v. 5.2.1, Bio-Rad Laboratories) was used to analyze the results, which included calculating the mean optical density (OD) of the negative control and the cut-off value for a positive sample (mean negative control OD +0.210 ). However, K. Wilson (microbiologist/TSE testing, Veterinary Diagnostics Laboratory, Colorado State University, Fort Collins, CO, personal communication) explained that their laboratory has reduced error associated with performing the assay that permits using an OD cut-off value of 0.100 . As a result, the OD value of 0.100 was used as the cut-off value for this study.

Western Blot Assay. The Western blot diagnostic assay was used to identify the presence of $\mathrm{PrP}^{\mathrm{Sc}}$ in the inocula of the different treatment groups. In addition, it was used to confirm the ELISA results of the 2- and 4 -mo killed mice $(\mathrm{n}=24)$ and a sample of end-stage clinical mice $(\mathrm{n}=13)$.

Samples were thawed at ambient temperature and sodium $N$-lauroyl sarkosinate was added to a final concentration of $0.1 \%$ (wt/vol). Thirty-microliter aliquots were removed and digested with 2 units Benzonase (EMD Chemicals Inc., San Diego, CA) as per manufacturer's instructions. Proteinase K (PK; New England Biolabs, Ipswich, MA) was added to a final concentration of 50 $\mu \mathrm{g} / \mathrm{mL}$ and digested at $37^{\circ} \mathrm{C}$ for $60 \mathrm{~min}$. The PK reactions were terminated by addition of Pefabloc [Pefabloc SC (AEBSF), Roche Applied Science, Indianapolis, IN] to $1 \mathrm{mM}$. Samples were prepared for electrophoresis by addition of Laemmli buffer to $1 \times$ concentration and incubated $\left(90^{\circ} \mathrm{C}\right)$ for 5 min. Samples were resolved via SDS-PAGE gel (4-15\% Tris HCl Ready Gel, BioRad Laboratories Inc., Hercules, CA) and transferred to polyvinylidene fluoride membranes (Immobilon- $\mathrm{P}^{\mathrm{SQ}}$ Transfer Membranes, Millipore Corp., Bedford, MA). Membranes were blocked in TBS-T (25 $\mathrm{m} M$ Tris, 140 $\mathrm{m} M \mathrm{NaCl}, 3 \mathrm{~m} M \mathrm{KCl}, 0.05 \%$ Tween-20, $\mathrm{pH}$ 8.0) plus $5 \%$ (wt/vol) nonfat milk-powder for $40 \mathrm{~min}$ at ambient temperature $\left(20^{\circ} \mathrm{C}\right)$ and exposed overnight $(8 \mathrm{~h}$; $\left.4^{\circ} \mathrm{C}\right)$ to $7 \mathrm{D} 9$ monoclonal prion protein $\operatorname{PrP}$ antibody (Abcam Inc., Cambridge, MA) in a 1:1,000-dilution of prion protein antibody to TBS-T plus $1 \%$ milk-powder solution. Membranes were washed 3 times ( 5 min each) with TBS-T and exposed to a 1:6,666 secondary HRPantibody dilution (Calbiochem Goat Anti-Mouse H\&L Chain Specific Peroxidase Conjugate, EMD Chemicals Inc., San Diego, CA) for $2 \mathrm{~h}$ at ambient temperature. Membranes were washed as above 3 more times and exposed to $1.2 \mathrm{~mL}$ of sensitivity substrate (SuperSignal West Femto Maximum Sensitivity Substrate, Thermo Fisher Scientific Inc., Waltham, MA) for 5 min. Membranes were photographed in a dark room (EpiChem Darkroon, UVP BioImaging Systems, UVP Inc., Upland, CA) and processed (Labworks45, UVP Inc.). The PVDF membranes were then stained with GelCode Blue Stain Reagent (Thermo Fisher Scientific Inc., Rockford, IL) for $20 \mathrm{~min}$, rinsed $10 \mathrm{~s}$ with $70 \%$ (vol/ vol) methanol, and dried at room temperature. This additional step was performed to ascertain whether any protein fragments and peptides remained after the rendering and alkaline hydrolysis treatments.

\section{Statistical Analysis}

The PROC LIFETEST procedure (SAS Inst. Inc., Cary, NC) was used for the survival analysis. The Log-Rank test explored the homogeneity of the survival curves (i.e., days to death) across the 4 treatment groups $(P<0.05)$. Fisher's exact test in the PROC FREQ procedure of SAS compared survival (i.e., delay in days to death) across the 4 treatment groups $(P<$ $0.05)$.

\section{RESULTS AND DISCUSSION}

The mouse model was initiated in December 2006. One mouse from the rendering treatment group died shortly after inoculation. Another mouse, this one from the alkaline hydrolysis treatment group, died unexpectedly at $150 \mathrm{~d}$ and was cannibalized before it could be removed from the cage; thus, its brain could not be collected for analysis. However, in the days before its death, the mouse did not display clinical signs of scrapie.

It was hypothesized that $\mathrm{PrP}^{\mathrm{Sc}}$ could be detected at 2 and or 4 mo postinoculation, which could have been used to establish a period of time from $\mathrm{PrP}^{\mathrm{Sc}}$ infection to manifestation of disease. Initially, a 6-mo euthanasia was scheduled also, but based on the disease-negative 
ELISA and Western blot diagnostic results from the 2and 4-mo mice (data not shown), it was decided that it would be more valuable to leave the 6 -mo mice in the study. Studies by White et al. (2003) and Pilon et al. (2007) identified the survival period for mice challenged by intraperitoneal injection with mouse-adapted scrapie that had originated from Rocky Mountain Laboratories to be approximately 190 to $220 \mathrm{~d}$.

The ELISA-based Bio-Rad CWD antigen test kit confirmed the presence of $\mathrm{PrP}^{\mathrm{Sc}}$ in mice that died of scrapie or were killed for displaying clinical signs of scrapie. Likewise, the ELISA confirmed that the negative control treatment group mice and alkaline hydrolysis treatment group mice, as well as the 6 rendering treatment group mice that lived to the end of the study, were negative for $\mathrm{PrP}^{\mathrm{Sc}}$ (data not shown). The CWD antigen test kit is not approved for detecting scrapie prions nor is it approved for confirming prion disease in laboratory rodents, but as discovered in this study, the CWD antigen test kit seems capable for detecting mouse-adapted scrapie prions.

The primary goal of preparing the rendering treatment group inoculum was to reproduce the physical conditions of continuous-flow rendering as closely as possible given the limitations of the laboratory setting and the small quantity of starting material. Precautions were taken to ensure that during the 45-min cooking treatment the peak temperature of the mouse brain homogenate did not exceed $135^{\circ} \mathrm{C}$. However, considering the aforementioned limitations, it is likely that the rendering process may have surpassed normal requirements because of the time-temperature relationship used in the rendering industry to guide commercial rendering processes. D. Kirstein (director of technical services, Darling International Inc., Des Moines, IA, personal communication) explained that the temperature of the raw material does not rise significantly until the water content is evaporated below $5 \%$, at which point the temperature increases expeditiously to 115 to $145^{\circ} \mathrm{C}$. Rendered material exiting the cooker must be, at a minimum, $115^{\circ} \mathrm{C}$; if this temperature is not achieved, the material is diverted from further processing and sent through the cooker again (D. Kirstein, director of technical services, Darling International Inc., Des Moines, IA, personal communication). Depending on the rendering system and the raw material undergoing treatment, this process generally requires 45 to 90 min of cooking (Anderson, 2006; D. Kirstein, director of technical services, Darling International Inc., Des Moines, IA, personal communication). Therefore, considering the small volume of starting material (i.e., one-third or $\sim 0.110 \mathrm{~g}$ of the scrapie-positive mouse brain homogenate) used for this treatment, it is likely that the temperature of the mouse brain homogenate reached $135^{\circ} \mathrm{C}$ well before the end of the cooking period. In fact, the temperature of the contents in the test tube reached $127^{\circ} \mathrm{C}$ within 5 min of being suspended in the beaker of heated shortening and was maintained at this approximate temperature until the final minutes of

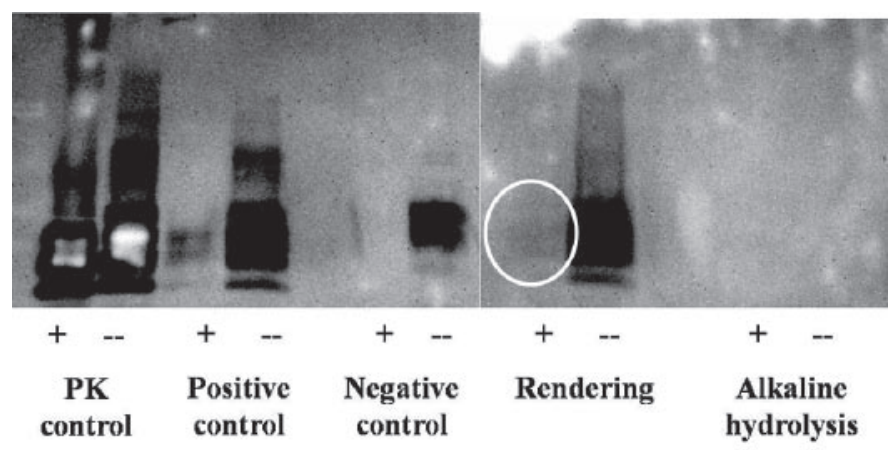

Figure 1. Western blot of the 4 treatment group inoculums analyzed with $(+)$ and without $(-)$ proteinase K (PK) digestion. Note: The circle is intended to identify the small amount of infectious prions $\left(\mathrm{PrP}^{\mathrm{Sc}}\right)$ that is believed to have survived the rendering treatment.

cooking when it was heated to its peak end-temperature of $135^{\circ} \mathrm{C}$ (data not shown). Under ideal circumstances, the excessive exposure of the mouse brain homogenate to the simulated rendering treatment would have been avoided by identifying an appropriate time-temperature relationship; however, given the outcome of the mouse model, the rendering treatment appears to have satisfied the needs of the study.

In Figure 1, the inoculum sample from the rendering treatment group that was not exposed to PK digestion maintained an unspecified quantity of normal prions, $\mathrm{PrP}^{\mathrm{Sc}}$, or both after treatment, which indicated that the rendering treatment did not cause excessive protein degradation. However, in the rendering treatment group inoculum sample that was exposed to PK digestion, there appeared to be a low level of $\operatorname{PrP}^{\mathrm{Sc}}$ that survived treatment (Figure 1). Results confirmed the suspicion that the rendering treatment was ineffective at eliminating all $\mathrm{PrP}^{\mathrm{Sc}}$ infectivity because the rendering treatment group mice experienced a 45 -d average delay in days to death ( 250 vs. $205 \mathrm{~d}$ for the positive control treatment group; $P<0.0001)$ and a $73.9 \%$ death loss $(P=0.0094 ;$ Figure 2). Specifically, rendering delayed, but did not stop, clinical mouse-adapted scrapie transmission.

Previous rendering studies by Taylor et al. (1995, 1997) achieved similar conclusions, in which they identified detectable infectivity in all scrapie-infected meat and bone meal samples and in 4 of 15 BSE-infected meat and bone meal samples after their respective rendering treatments. Infectivity was recovered in all samples subjected to the continuous-flow rendering treatments. Appel et al. (2001) reported that lipids protected prion rods against peptide-bond cleavage during autoclaving, which required increasing the autoclave temperature for prion rod samples that contained tallow to $170^{\circ} \mathrm{C}$ for $20 \mathrm{~min}$ to surpass the $\mathrm{PrP}^{\mathrm{Sc}}$ inactivation threshold. The peak temperature of the simulated continuous cooker never exceeded $138^{\circ} \mathrm{C}$. Although the mouse brain homogenate was cooked close to this temperature for $45 \mathrm{~min}$ - exceeding the necessary 20 -min period; it is plausible that the temperature inactivation threshold of $\mathrm{PrP}^{\mathrm{Sc}}$ was not close enough to being breeched 


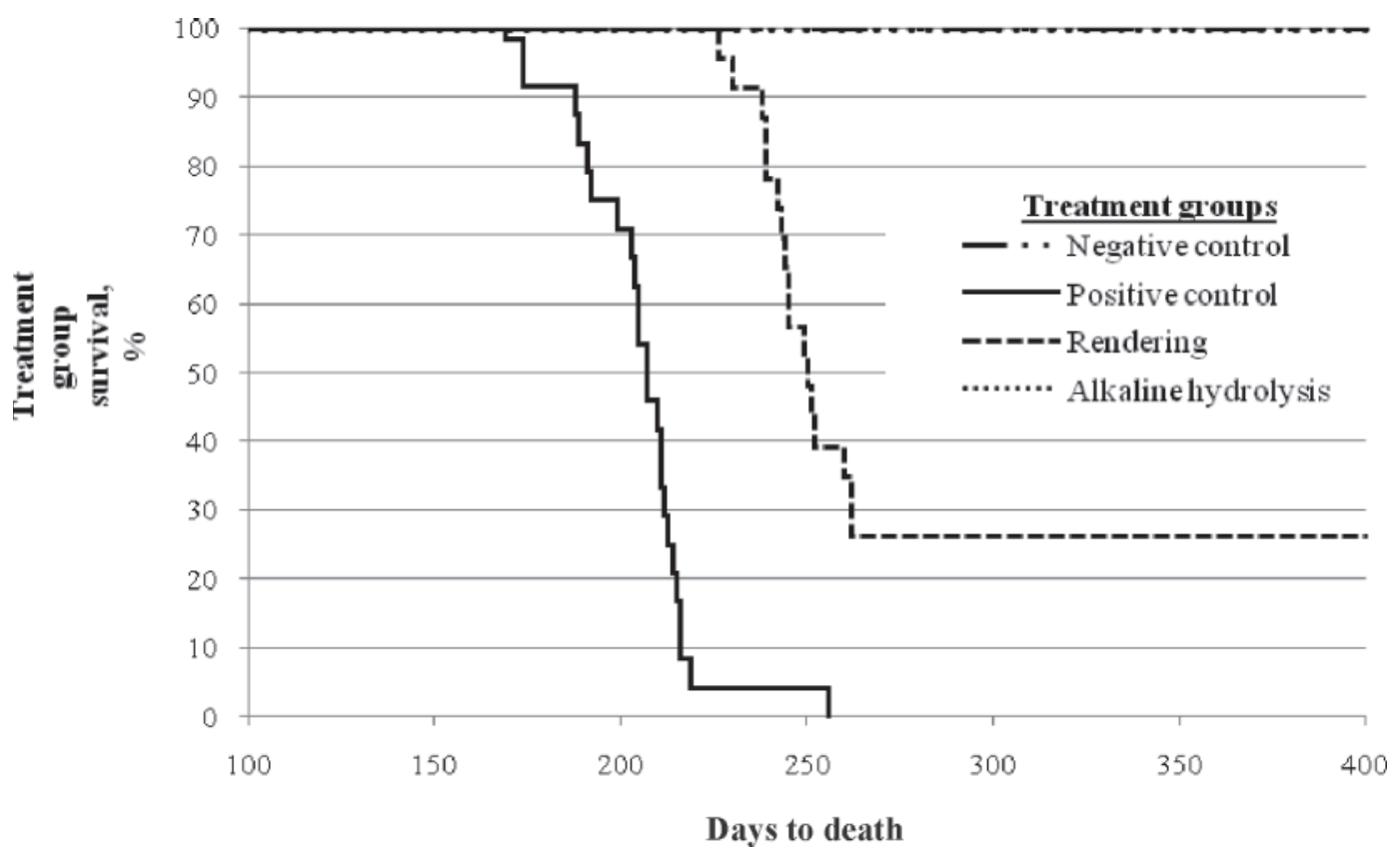

Figure 2. Survival curves for mouse treatment groups inoculated with infectious prions $\left(\mathrm{PrP}^{\mathrm{Sc}}\right)$-negative mouse brain material; $\mathrm{PrP}^{\mathrm{Sc}}$-positive mouse brain material; rendered $\mathrm{PrP}^{\mathrm{Sc}}$-positive mouse brain material; or hydrolyzed $\mathrm{PrP}^{\mathrm{Sc}}$-positive mouse brain material.

to completely eliminate all infectivity, thereby creating the potential for $\mathrm{PrP}^{\mathrm{Sc}}$ to survive rendering and propagate the disease.

Finally, the mouse model confirmed the efficacy of alkaline hydrolysis to inactivate $\operatorname{PrP}^{\mathrm{Sc}}$ because no mice succumbed to the disease (Figure 2). The alkaline hydrolysis process degraded all proteins, including $\operatorname{PrP}^{\mathrm{Sc}}$, into small peptides and $\mathrm{AA}$, which likely extended past the end of the gel during protein separation (Figure 1). This argument was further supported by the results from staining the PVDF membranes with GelCode Blue, which did not identify any residual protein fragments and peptides in the lanes used for separating the alkaline hydrolysis treatment group inoculum samples (data not shown). The alkaline hydrolysis process demonstrated its potential as a superior alternative to rendering for disposing of biological materials potentially infected or contaminated with $\operatorname{PrP}^{\mathrm{Sc}}(P<0.0001)$. Taylor and Woodgate (2003) reported that hot alkali processes, like alkaline hydrolysis, are among the few disposal methods approved by the European Union and World Health Organization for inactivating infectious prions.

The scrapie-positive mouse brain homogenate was treated for $65 \mathrm{~h}$, which exceeded the 6 -h processing time required by the European Commission Scientific Steering Committee for inactivating prions by almost 11 times (Thacker, 2004). Ideally, the length of time the mouse brain homogenate was hydrolyzed would have been closer to $6 \mathrm{~h}$, but because of factors beyond our control and because of our interest in validating this specific alkaline hydrolysis process in its entirety, this was not possible. More specifically, the mouse brain homogenate was hydrolyzed in a prototype or beta testversion of the BioMEER alkaline hydrolysis unit. Since that time (December 2006), technological advances and advances in cycle optimization should reduce complete process times to between 24 to $36 \mathrm{~h}$ (K. Morris, owner and chief operating officer, Hydrol-Pro Technologies Inc., Zephyr Hills, FL, personal communication). In addition, it should be noted that the infrastructure at the veterinary hospital that was responsible for heating and cooling the alkaline hydrolysis unit was not engineered to accommodate such strenuous demands, which may have hindered the efficiency of the process. For example, the alkaline hydrolysis unit did not reach its peak operating temperature until 9 to $12 \mathrm{~h}$ after the process was initiated.

The enhanced feed ban of the FDA is set to take effect April 27, 2009; as a consequence, the animal rendering and beef packing industries will need to identify alternative methods for disposing of these potentially infectious materials. We calculated during the study that the cost of using alkaline hydrolysis to dispose of animal tissues and carcasses was approximately $\$ 0.26$ to $\$ 0.31 / \mathrm{kg}$ ( $\$ 0.12$ to $\$ 0.14 / \mathrm{lb})$. However, this cost did not include the initial capital investment of purchasing an alkaline hydrolysis unit, as well as the cost of building or renovating a facility to accommodate such a unit.

Therefore, if the financial costs of this technology are acceptable, alkaline hydrolysis should be considered by the animal rendering and beef packing industries as an alternative to incineration, landfill burial, and rendering for disposing of biological material potentially infected or contaminated with prion disease. In addition, compared with incineration and landfill burial, alkaline hydrolysis yields a sterilized proteinaceous end product (effluent) that may have some commercial value such as a carbon source for composting and anaerobic digestion, 
which could be sold to recuperate expenses incurred through its operation. If the effluent were used for one of these purposes, it may not be necessary to perform the wastewater removal step, which could drastically reduce the amount of time required to complete one alkaline hydrolysis process.

\section{LITERATURE CITED}

Anderson, D. P. 2006. Essential rendering. All about the animal byproducts industry. D. L. Meeker, ed. Kirby Lithographic Company Inc., Arlington, VA.

Appel, T. R., M. Wolff, F. von Rheinbaben, M. Heinzel, and D. Riesner. 2001. Heat stability of prion rods and recombinant prion protein in water, lipid and lipid-water mixtures. J. Gen. Virol. 82:465-473.

DHHS-FDA. 2008. Department of Health and Human Services, Food and Drug Administration, April 25, 2008. 21 CFR Part 589 [Docket No. FDA-2002-N-0031 (formerly 2002N-0273)] RIN 0910-AF46. "Substances prohibited from use in animal food or feed; Final Rule", Final Rule. Fed. Regist. 73:22719-22758.

Hamir, A. N., R. A. Kunkle, J. A. Richt, J. M. Miller, and J. J. Greenlee. 2008. Experimental transmission of US scrapie agent by nasal, peritoneal, and conjunctival routes to genetically susceptible sheep. Vet. Pathol. 45:7-11.

Hibler, C. P., K. L. Wilson, T. R. Spraker, M. W. Miller, R. R. Zink, L. L. DeBuse, E. Anderson, D. Schweitzer, J. A. Kennedy, L. A. Baeten, J. F. Smeltzer, M. D. Salman, and B. E. Powers. 2003. Field validation and assessment of an enzyme-linked immunosorbent assay for detecting chronic wasting disease in mule deer (Odocoileus hemionus), white-tailed deer (Odocoileus virginianus), and Rocky Mountain elk (Cervus elaphus nelsoni). J. Vet. Diagn. Invest. 15:311-319.

Pilon, J., C. Loiacono, D. Okeson, S. Lund, K. VerCauteren, J. Rhyan, and L. Miller. 2007. Anti-prion activity generated by a novel vaccine formulation. Neurosci. Lett. 429:161-164.
Roeber, D. L., P. D. Mies, C. D. Smith, K. E. Belk, T. G. Field, J. D. Tatum, J. A. Scanga, and G. C. Smith. 2001. National market cow and bull beef quality audit-1999: A survey of producer-related defects in market cows and bulls. J. Anim. Sci. 79:658-665.

Taylor, D. M., and S. L. Woodgate. 2003. Rendering practices and inactivation of transmissible spongiform encephalopathy agents. Rev. Sci. Tech. Off. Int. Epizoot. 22:297-310.

Taylor, D. M., S. L. Woodgate, and M. J. Atkinson. 1995. Inactivation of the bovine spongiform encephalopathy agent by rendering procedures. Vet. Rec. 137:605-610.

Taylor, D. M., S. L. Woodgate, A. J. Fleetwood, and R. J. G. Cawthorne. 1997. Effect of rendering procedures on the scrapie agent. Vet. Rec. 141:643-649.

Thacker, H. L. 2004. Alkaline hydrolysis. Carcass disposal: A comprehensive review. National Agricultural Biosecurity Center, Kansas State University. http://129.130.129.231/FeaturedContent/CarcassDisposal/PDF\%20Files/CH\%206\%20-\%20Alkaline\%20Hydrolysis.pdf Accessed 12/13/2008.

USDA-NASS. 2008a. United States Department of Agriculture, National Agricultural Statistics Service. Livestock Slaughter 2007 Summary, March 2008. http://usda.mannlib.cornell.edu/usda/ current/LiveSlauSu/LiveSlauSu-03-07-2008_revision.pdf Accessed $12 / 12 / 2008$.

USDA-NASS. 2008b. United States Department of Agriculture, National Agricultural Statistics Service. Meat Animals Production, Disposition, and Income 2007 Summary, April 2008. http://usda.mannlib.cornell.edu/usda/current/MeatAnimPr/ MeatAnimPr-04-25-2008.pdf Accessed 12/12/2008.

White, A. R., P. Enever, M. Tayebi, R. Mushens, J. Linehan, S. Brandner, D. Anstee, J. Collinge, and S. Hawke. 2003. Monoclonal antibodies inhibit prion replication and delay the development of prion disease. Nature 422:80-83. 